\title{
(6) OPEN ACCESS \\ Childhood secondhand smoke exposure and pregnancy loss in never smokers: the Guangzhou Biobank Cohort Study
}

\author{
Shanshan Yang, ${ }^{1,2}$ Lin $\mathrm{Xu}_{1}{ }^{3}$ Yao He, ${ }^{1,4,5}$ Chaoqiang Jiang, ${ }^{6}$ Yali Jin, ${ }^{6}$ \\ Kar Keung Cheng, ${ }^{7}$ Weisen Zhang, ${ }^{6}$ Tai Hing Lam ${ }^{1,3,6}$
}

'Institute of Geriatrics, Chinese PLA General Hospital, Beijing, China

${ }^{2}$ Jinan Military Area CDC, Jinan, Shandong, China

${ }^{3}$ School of Public Health, the University of Hong Kong, Hong Kong, China

${ }^{4}$ Beijing Key Laboratory of Aging and Geriatrics, Chinese PLA General Hospital, Beijing, China ${ }^{5}$ State Key Laboratory of Kidney Disease, Chinese PLA General Hospital, Beijing, China

${ }^{6}$ Guangzhou Number 12 People's Hospital, Guangzhou, China

Public Health, Epidemiology and Biostatistics, University of Birmingham, Birmingham, UK

\section{Correspondence to}

Professor Yao He, Institute of Geriatrics, Chinese PLA General Hospital, 28 Fuxing Road, Beijing 100853, China: yhe301@x263.net

SY and LX contributed equally.

Received 7 June 2016 Revised 1 October 2016 Accepted 1 November 2016 Published Online First 23 December 2016

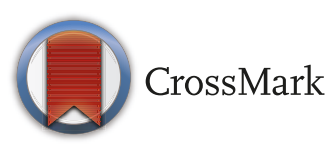

To cite: Yang $S, X u L$, He Y, et al. Tob Control

2017;26:697-702

\section{ABSTRACT}

Objective Studies of secondhand smoke (SHS) exposure especially childhood SHS exposure and pregnancy loss are limited. We used baseline data of the Guangzhou Biobank Cohort Study (GBCS) to examine the association of childhood SHS exposure with a history of pregnancy loss.

Methods Never smoking women aged 50 years or above in GBCS from 2003 to 2008 were included. Propensity score matching (PSM) was used to control for confounding. Negative binomial regression and logistic regression were used to examine the association of childhood SHS, assessed by number of smokers in childhood household and frequency of exposure, with past pregnancy loss.

Results Of 19562 women, 56.7\% (11 096) had SHS exposure during childhood. In negative binomial regression, after adjusting for age, education, past occupational dust exposure, past home fuel exposure, oral contraceptive, adulthood SHS exposure, age at first pregnancy and age at first menarche, compared to nonexposure, the incidence rate ratio of one more pregnancy loss was 1.20 (95\% Cl1.05 to 1.37) in those who lived with $\geq 2$ smokers in the same household, and 1.14 (95\% Cl 1.04 to 1.25 ) in those exposed $\geq 5$ times/week. After similar adjustment, logistic regression showed that the OR of pregnancy loss $\geq 2$ times (versus 0 to 1 time) was $1.25(95 \% \mathrm{Cl} 1.00$ to 1.57$)$ and $1.20(95 \% \mathrm{Cl}$ 1.03 to 1.40 ) for high density ( $\geq 2$ smokers in the same household) and frequency ( $\geq 5$ times/week) of childhood exposure, respectively.

Conclusions Childhood SHS exposure was associated with higher risks of pregnancy loss in middle-aged and older Chinese women.

\section{INTRODUCTION}

The prevalence of pregnancy loss, defined as the death of an embryo or fetus before it is able to survive independently, was $17.3 \%$ in American women of childbearing age aged 24-44 years ${ }^{1}$ in 1992-2009 and 4.36-12.2\% in Chinese women of childbearing age (20-49 years) in 1988-1997. ${ }^{2}$ There were several possible explanations for pregnancy loss, such as occupational and environmental exposure and unhealthy lifestyle factors. ${ }^{3}$ Active smoking in pregnant women or their husbands was associated with a higher risk of pregnancy loss, and the risk was greater for smoking during pregnancy. ${ }^{4}$

Compared with directly inhaled tobacco smoke or mainstream smoke, the evidence indicates that undiluted sidestream smoke, the major contributor to secondhand smoke (SHS), contains higher levels of chemical compounds considered to be carcinogenic or toxic-including benzene, formaldehyde, catechol and $\mathrm{N}$-nitrosamines. ${ }^{5}$ Concerns about the harmful effects of SHS have been increasing. Some previous studies showed that maternal ${ }^{6-8}$ or prenatal $^{9}$ SHS exposure in adulthood was associated with a higher risk of pregnancy loss, but only a few examined the association between childhood SHS exposure and pregnancy loss. ${ }^{10-12}$ Since childhood is a sensitive stage, such exposure to exogenous harmful substances, during this period may lead to adverse health outcomes in adulthood. ${ }^{13}{ }^{14}$ Animal and human studies found that exposure to tobacco smoke adversely affected embryo development, ${ }^{15}$ suggesting that SHS exposure during childhood may increase the risk of pregnancy loss at reproductive age. However, evidence from populationbased studies on childhood SHS exposure and pregnancy loss in adulthood is limited. We found only one community-based study from the USA showing a positive association of SHS exposure in childhood and adulthood with the risk of pregnancy loss. ${ }^{10}$ To the best of our knowledge, there are no reports from Asian populations. In China, $98 \%$ women were never smokers ${ }^{15}$ but $70.5 \%$ of them ${ }^{16}$ were exposed to SHS in 2010. Thus, we examined the association of childhood SHS exposure with pregnancy loss in the Guangzhou Biobank Cohort Study (GBCS), the largest population-based cohort study of middle-aged and older Chinese people in southern China.

\section{METHODS}

\section{Guangzhou Biobank Cohort Study}

We used GBCS baseline data for the present analysis. Details of the methods have been reported elsewhere. ${ }^{17}$ Briefly, GBCS is a collaborative project among the Guangzhou 12th Hospital and the Universities of Hong Kong and Birmingham. It is an ongoing prospective cohort study on permanent Guangzhou residents aged 50 years or above, and aims to examine environmental and genetic determinants of chronic diseases. Participants were recruited from a community social and welfare association, the Guangzhou Health and Happiness Association for the Respectable Elders, which is a large unofficial organisation aligned with the Guangzhou municipal government and has more than 150 branches and 100000 members. Those receiving treatment for life-threatening diseases such as cancer, or who did not provide informed consent, were excluded. Information on smoking, SHS exposure (adult and childhood), personal 
disease history and other factors were collected by face-to-face computer-assisted interview.

GBCS was approved by the Medical Ethics Committee of the Guangzhou Medical Association. All participants provided written informed consent before joining the study.

\section{Measurement}

Information on socioeconomic position and lifestyle including age, sex, education, oral contraceptive use, smoking and alcohol use was collected by a computer-assisted standardised questionnaire administered by trained interviewers. Education was assessed and classified into three groups: $\leq$ Primary school $(0-$ 6 years), Middle school (7-12 years), $\geq$ College ( $\geq 13$ years). Oral contraceptive use was self-reported, and the question was as follows: Have you ever used oral contraceptives before? Childhood was defined as the period between infancy and adulthood (28 days to 18 years). This is the usual definition of childhood in the Chinese population.

\section{Exposure}

A never smoker was defined as one who had smoked $<100$ cigarettes in her lifetime. ${ }^{18}$ Childhood SHS exposure was defined as living with one or more smokers and being exposed to the smoker's tobacco smoke for at least $15 \mathrm{~min} /$ day on more than 1 day/week in the same household during childhood. ${ }^{4}$ Two self-reported SHS measures were used. The first was density, defined by the presence of none, one or two or more smokers living in the same household when the participant was a child. The other was frequency, categorised into no exposure, low $(<5$ times/week) and high ( $\geq 5$ times/week) levels of exposure (one time of exposure was defined as exposure $\geq 5$ consecutive minutes). The density and frequency of childhood SHS exposure based on the questions were shown to be associated with young age at menarche in GBCS. ${ }^{19}$

\section{Study outcome}

Pregnancy loss was defined as the death of an embryo or fetus before it is able to survive independently. ${ }^{20}$ Information on times of pregnancy loss was obtained by self-report. Frequent pregnancy loss was defined as pregnancy loss of $\geq 2$ times (versus 0 to 1 ). Sensitivity analysis was conducted using a cut-off of 3 times ( $<3$ vs $\geq 3$ times).

\section{Statistical analysis}

We compared the demographic characteristics between participants with and without childhood SHS exposure using t-test and $\chi^{2}$ test. Logistic regression was used to examine associations of childhood SHS exposure with pregnancy loss.

Propensity score matching (PSM) 21 was performed to control for differences in baseline characteristics between those with and without childhood SHS exposure. Multivariable logistic regression including age, education, past occupational dust exposure, past home fuel exposure, oral contraceptive, adulthood SHS exposure, age at first pregnancy and age at first menarche was used to obtain propensity scores for each individual. These potential confounders were selected according to their association with pregnancy loss on the basis of clinical knowledge and previous studies. ${ }^{23} 24$ We then performed nearest neighbour matching of the two groups at a $1: 1$ fixed ratio, using a caliper width of 0.2 of the SD of the logit of the propensity score. Balance achieved by matching was assessed by examining differences in baseline variables between the childhood exposure group and no childhood exposure group before and after PSM. Negative binomial regression analysis was used to examine the association between childhood SHS exposure and the times of pregnancy loss (counts). Univariate analysis, logistic regression and propensity score matching were conducted by SPSS V.19.0 and negative binomial regression analysis was conducted by Stata V.12.0. A two tailed $\mathrm{p}<0.05$ was considered statistically significant.

\section{Patient involvement}

No patients were involved in setting the research question or the outcome measures, and nor were they involved in the design and implementation of the study. There are no plans to involve patients in dissemination.

\section{RESULTS}

Of 30518 participants of GBCS recruited from September 2003 to January 2008, 20903 (68.5\%) were female never smokers. After excluding 842 women with missing information on pregnancy loss and 499 women with infertility, 19562 were included in the present analysis (figure 1). A total of $866(4.4 \%)$ had pregnancy loss $\geq 2$ times and $267(1.4 \%) \geq 3$ times. The mean age at first pregnancy was 24.7 (SD 3.6) years, and at first menarche was 15.1 (SD2.1) years (Table not shown).

Table 1 shows that 56.7\% (11096/19 562) women were exposed to SHS during childhood. Those with childhood SHS exposure were younger, had a lower level of education and prevalence of past home fuel exposure and adulthood SHS exposure, but had a higher prevalence of past occupational dust exposure and use of oral contraceptive than those without exposure (table 1). They also had a younger age at first menarche $(14.9$ vs 15.3 years, $\mathrm{p}<0.001)$ and an older age at first pregnancy $(25.0$ vs 24.5 years, $\mathrm{p}<0.001)$. After matching on the propensity score $(n=7782$ for each group, total included: 15564 ), the SD of the logit of the propensity score width was $<0.2$, suggesting a successful matching. ${ }^{25}$

Table 2 model 2 shows that, after adjusting for age, education, past occupational dust exposure, past home fuel exposure, oral contraceptive, adulthood SHS exposure, age at first pregnancy and age at first menarche, compared to non-exposure, the incidence rate ratio (IRR) for one more pregnancy loss in those with childhood SHS exposure was 1.20 (95\% CI1.05 to 1.37) for those who lived with $\geq 2$ smokers in the same household and 1.14 (95\% CI 1.04 to 1.25 ) for those with an exposure frequency of $\geq 5$ times/week.

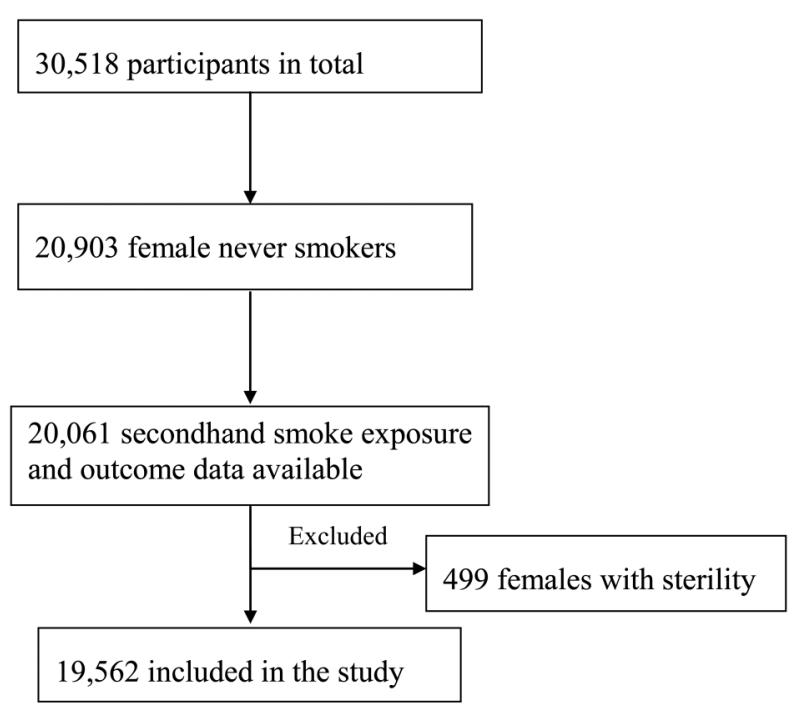

Figure 1 Flow diagram of the study population. 
Table 1 Demographic characteristics of the participants by childhood secondhand smoke exposure at home before and after PSM

\begin{tabular}{|c|c|c|c|c|c|c|c|}
\hline & \multirow{2}{*}{$\begin{array}{l}\text { Number }(\%) \\
\text { Total N=19 } 562\end{array}$} & \multicolumn{3}{|c|}{ Childhood home exposure (before PSM) } & \multicolumn{3}{|c|}{ Childhood home exposure (after PSM) } \\
\hline & & Yes $(n=11096)$ & None $(n=8466)$ & p & Yes $(n=7782)$ & None $(n=7782)$ & p Value \\
\hline Age (years) & & & & $<0.001$ & & & 0.50 \\
\hline $50-59$ & $10025(51.3)$ & $6502(58.6)$ & $3523(41.6)$ & & $3555(45.7)$ & $3522(45.3)$ & \\
\hline $60-69$ & $7184(36.7)$ & $3618(32.6)$ & $3566(42.1)$ & & $3267(42.0)$ & $3333(42.8)$ & \\
\hline$\geq 70$ & $2353(12.0)$ & $976(8.8)$ & $1377(16.3)$ & & $960(12.3)$ & $927(11.9)$ & \\
\hline Education & & & & $<0.001$ & & & 0.68 \\
\hline$\leq$ Primary school & $9157(46.8)$ & $4981(44.9)$ & $4176(49.3)$ & & $3711(47.7)$ & $3691(47.4)$ & \\
\hline Middle school & $9232(47.2)$ & 5510 (49.7) & $3722(44.0)$ & & $3566(45.8)$ & $3559(45.7)$ & \\
\hline$\geq$ College & $1173(6.0)$ & $605(5.5)$ & $568(6.7)$ & & $505(6.5)$ & $532(6.8)$ & \\
\hline Past occupational dust exposure & & & & $<0.001$ & & & 0.20 \\
\hline Yes & $936(4.8)$ & $613(5.5)$ & $323(3.8)$ & & $346(4.4)$ & $314(4.0)$ & \\
\hline None & $18626(95.2)$ & $10483(94.5)$ & $8143(96.2)$ & & 7436 (95.6) & $7468(96.0)$ & \\
\hline Past home fuel exposure & & & & 0.49 & & & $<0.001$ \\
\hline Yes & $9405(48.1)$ & $5311(47.9)$ & $4094(48.4)$ & & $4056(52.1)$ & $3720(47.8)$ & \\
\hline None & $10157(51.9)$ & $5785(52.1)$ & $4372(51.6)$ & & $3726(47.9)$ & $4062(52.2)$ & \\
\hline Oral contraceptive & & & & $<0.001$ & & & 0.001 \\
\hline Yes & 3539 (18.1) & $2152(19.4)$ & $1387(16.4)$ & & 1490 (19.1) & $1334(17.1)$ & \\
\hline None & $16023(81.9)$ & 8944 (80.6) & 7079 (83.6) & & $6292(80.9)$ & $6448(82.9)$ & \\
\hline Adulthood home exposure & & & & $<0.001$ & & & 0.70 \\
\hline Yes & $4182(21.4)$ & $2026(18.3)$ & $2156(25.5)$ & & $1750(22.5)$ & $1730(22.2)$ & \\
\hline None & $15380(78.6)$ & 9070 (81.7) & $6310(74.5)$ & & $6032(77.5)$ & $6052(77.8)$ & \\
\hline \multicolumn{8}{|l|}{ Childhood home exposure } \\
\hline None & $8466(43.3)$ & & & & $7782(100.0)$ & $7782(100.0)$ & \\
\hline Yes & $11096(56.7)$ & & & & & & \\
\hline \multicolumn{8}{|l|}{ Number of home smokers } \\
\hline One & $8504(43.5)$ & 8504 (76.6) & & & $5938(76.3)$ & & \\
\hline Two or more & $2592(13.3)$ & $2592(23.4)$ & & & $1844(23.7)$ & & \\
\hline \multicolumn{8}{|l|}{ Frequency of exposure } \\
\hline$<5$ times/week & $2790(14.3)$ & $2790(25.1)$ & & & $1925(24.7)$ & & \\
\hline$\geq 5$ times/week & $8306(42.5)$ & $8306(74.9)$ & & & $5857(75.3)$ & & \\
\hline
\end{tabular}

Table 3 model 2 shows that, after similar adjustment, compared to non-exposure, both high density (childhood SHS exposure $\geq 2$ smokers in the same household) and high frequency of exposure ( $\geq 5$ times/week) were associated with a higher risk of frequent pregnancy loss ( $\geq 2$ times vs $0-1$ time) (OR $1.25,95 \%$ CI 1.00 to 1.57 , and 1.20 , 95\% CI 1.03 to 1.40 , respectively).

Sensitivity analysis using pregnancy loss $\geq 3$ times as the definition of frequent pregnancy loss showed similar results for frequency $\geq 5$ times/week (adjusted OR 1.30, 95\% CI 1.00 to 1.71; table 3).

\section{DISCUSSION}

Based on GBCS baseline data, we have shown that never smoking women exposed to SHS during childhood, particularly with higher density (greater number of smokers) and frequency, were associated with higher risks of pregnancy loss in adulthood. To the best of our knowledge, this is the first study showing the association in Asians. The major strength of our study was the comprehensive control and adjustment of a wide range of potential confounders using different statistical models. The similar results demonstrated the robustness of the results. Moreover, since childhood SHS exposure undoubtedly occurred before pregnancy loss, the problem of reverse causality, one of the major limitations in cross-sectional studies, should not be a major concern in our study.
Several previous studies showed that maternal SHS exposure in adulthood was associated with pregnancy loss, ${ }^{6-8}$ but only a few examined the association between childhood SHS exposure and pregnancy loss. ${ }^{10-12}$ Meeker et al ${ }^{12}$ recruited 2162 nonsmoking women from couples undergoing in vitro fertilisation or intra cytoplasmic sperm injection in three Boston, Massachusetts area clinics from August 1994 to June 2003 and found that women who reported having two parents who smoked during their childhood were associated with an increased risk of spontaneous abortion compared to those without such exposure (OR 1.8, 95\% CI 1.0 to 3.0).However, information of SHS exposure frequency was not reported. Peppone et al showed that in women who visited a cancer hospital, SHS exposure both at home during childhood and at the time of the survey was associated with fetal loss (OR 1.39, 95\% CI 1.17 to 1.66 ). However, the association of childhood SHS exposure with fetal loss was not statistically significant, probably because of the relatively small sample size $(n=4794) .{ }^{11}$ Hyland et $a l^{10}$ analysed historical reproductive data of 80762 women from the Women's Health Initiative Observational Study in the USA and showed that in never-smoking women, compared to those without SHS exposure, those with the highest levels of lifetime SHS exposure, defined as childhood exposure $>10$ years, adulthood home exposure $>20$ years and/or adulthood work exposure $>10$ years, had a higher risk of spontaneous abortion (OR 1.17, 95\% CI 1.05 to 1.30 ). However, the 
Table 2 IRR of pregnancy loss times (counts) from childhood secondhand smoke exposure in female never smokers by negative binominal regression (after PSM)

\begin{tabular}{|c|c|c|c|c|}
\hline & \multirow[b]{2}{*}{$\mathrm{N}$} & \multicolumn{3}{|l|}{ IRR $(95 \% \mathrm{CI})$} \\
\hline & & Crude model & Model 1 & Model 2 \\
\hline \multicolumn{5}{|l|}{ Number of smokers } \\
\hline None (reference) & 7782 & 1 & 1 & 1 \\
\hline 1 smoker & 5938 & 1.02 (0.93 to 1.12$)$ & $1.03(0.94$ to 1.14$)$ & $1.03(0.94$ to 1.13$)$ \\
\hline$\geq 2$ smokers & 1844 & $1.18(1.03 \text { to } 1.35)^{*}$ & $1.21(1.06 \text { to } 1.38)^{*}$ & $1.20(1.05 \text { to } 1.37)^{*}$ \\
\hline$P$ for trend & & 0.03 & 0.01 & 0.02 \\
\hline \multicolumn{5}{|c|}{ Frequency of exposure } \\
\hline None (reference) & 7782 & 1 & 1 & 1 \\
\hline$<5$ times/week & 1925 & 0.82 (0.71 to 0.95$)$ & 0.84 (0.72 to 0.97$)$ & $0.84(0.73$ to 0.97$)$ \\
\hline$\geq 5$ times/week & 5857 & $1.14(1.04 \text { to } 1.25)^{*}$ & $1.15(1.05 \text { to } 1.26)^{*}$ & $1.14(1.04 \text { to } 1.25)^{*}$ \\
\hline$P$ for trend & & 0.007 & 0.004 & 0.006 \\
\hline \multicolumn{5}{|c|}{$\begin{array}{l}{ }^{*} \mathrm{p}<0.05 . \\
\text { Model 1: Adjusted for age. } \\
\text { Model 2: Adjusted for age, education, past occupational dust exposure, past home fuel exposure, oral contraceptive, adulthood passive smoke exposure, age at first pregnancy and age } \\
\text { at first menarche. } \\
\text { IRR, incidence rate ratio; PSM, propensity score matching. }\end{array}$} \\
\hline
\end{tabular}

Table 3 OR of frequent pregnancy loss ( $\geq 2$ or $\geq 3$ times) from childhood secondhand smoke exposure in female never smokers by logistic regression (after PSM)

\begin{tabular}{|c|c|c|c|c|}
\hline & \multirow[b]{2}{*}{ Number (\%) } & \multicolumn{3}{|l|}{ OR $(95 \% \mathrm{CI})$} \\
\hline & & Crude model & Model 1 & Model 2 \\
\hline \multicolumn{5}{|l|}{ Pregnancy loss $\geq 2$} \\
\hline \multicolumn{5}{|l|}{ Number of smokers } \\
\hline None (reference) & $360(4.6)$ & 1 & 1 & 1 \\
\hline 1 smoker & $293(4.9)$ & $1.07(0.91$ to 1.25$)$ & 1.09 (0.93 to 1.27$)$ & 1.07 (0.91 to 1.26$)$ \\
\hline$\geq 2$ smokers & $104(5.6)$ & $1.23(0.99$ to 1.54$)$ & $1.27(1.01 \text { to } 1.59)^{*}$ & $1.25(1.00 \text { to } 1.57)^{*}$ \\
\hline $\mathrm{P}$ for trend & & 0.08 & 0.04 & 0.06 \\
\hline \multicolumn{5}{|c|}{ Frequency of exposure } \\
\hline None (reference) & $360(4.6)$ & 1 & 1 & 1 \\
\hline$<5$ times/week & $72(3.7)$ & $0.80(0.62$ to 1.04$)$ & 0.84 (0.65 to 1.08$)$ & 0.84 (0.65 to 1.09$)$ \\
\hline$\geq 5$ times/week & $325(5.5)$ & $1.21(1.04 \text { to } 1.41)^{*}$ & $1.22(1.05 \text { to } 1.43)^{*}$ & $1.20(1.03 \text { to } 1.40)^{*}$ \\
\hline$P$ for trend & & 0.02 & 0.01 & 0.03 \\
\hline \multicolumn{5}{|l|}{ Pregnancy loss $\geq 3$} \\
\hline \multicolumn{5}{|l|}{ Number of smokers } \\
\hline None (reference) & $108(1.4)$ & 1 & 1 & 1 \\
\hline 1 smoker & $97(1.6)$ & $1.18(0.90$ to 1.56$)$ & 1.19 (0.91 to 1.57$)$ & 1.18 (0.89 to 1.55$)$ \\
\hline$\geq 2$ smokers & $28(1.5)$ & $1.10(0.72$ to 1.67$)$ & $1.12(0.74$ to 1.71$)$ & $1.09(0.72$ to 1.67$)$ \\
\hline $\mathrm{P}$ for trend & & 0.39 & 0.33 & 0.46 \\
\hline \multicolumn{5}{|c|}{ Frequency of exposure } \\
\hline None (reference) & 108 (1.4) & 1 & 1 & 1 \\
\hline$<5$ times/week & $18(0.9)$ & $0.67(0.41$ to 1.11$)$ & $0.70(0.42$ to 1.15$)$ & $0.70(0.42$ to 1.15$)$ \\
\hline$\geq 5$ times/week & $107(1.8)$ & $1.32(1.01 \text { to } 1.73)^{*}$ & $1.33(1.02 \text { to } 1.74)^{*}$ & $1.30(1.00 \text { to } 1.71)^{*}$ \\
\hline$P$ for trend & & 0.05 & 0.04 & 0.06 \\
\hline
\end{tabular}

authors did not distinguish childhood SHS exposure from adulthood SHS exposure. Thus, our results are consistent with the studies above and have provided new evidence supporting a positive association between childhood SHS exposure and the risk of pregnancy loss.

The mechanistic pathway of how childhood SHS exposure may lead to pregnancy loss is still unclear. However, earlier evidence has shown the toxic effects of active smoking on pregnancy and fertility. ${ }^{26}{ }^{27}$ In vitro studies have reviewed the mechanistic pathways including the effects of active smoke exposure on uterine micro vasculature, cytotrophoblast invasion, mitotic activity, differentiation and attachment during placental development and on embryonic development. ${ }^{28}$ In vivo studies also suggested that tobacco compounds exert a deleterious effect on the 
process of ovarian follicle maturation. ${ }^{29}$ Furthermore, some previous studies showed that SHS might alter endocrine and menstrual function in women. ${ }^{30}{ }^{31}$ Maternal smoking exposure was associated with retarded embryo growth in the uterus. ${ }^{32}$ Since childhood is the critical development stage of all tissues, organs and systems, and children's lungs and immune system are immature, they are vulnerable to the adverse effects of SHS exposure and may subsequently suffer from adverse health outcomes in adulthood including pregnancy loss.

This study had several limitations. Since the information on exposure and pregnancy loss was based on recall, random error could not be fully ruled out, which may lead to a bias towards null. Although differential reporting of exposure was possible, the reliability of the questionnaire was tested in 200 participants with $\kappa$ values of 0.88 and 0.96 for the two questions about smoking status, respectively. ${ }^{17} 33$ Second, our sample may not be completely representative of the general older populations in southern China. However, within sex and age group, the participants had a fairly similar prevalence of chronic diseases such as diabetes and hypertension to nationally representative samples of urban Chinese. ${ }^{17}$ The representativeness of our sample should not affect the internal validity substantially in the present study. The third limitation is the lack of information on the sources of childhood SHS exposure. However, since very few women smoke $(<2 \%)$ in China, 16 most of the childhood SHS exposure was from paternal smoking. Fourth, we did not have information to assess the association of genetic abnormality with pregnancy loss. However, since chromosomal abnormality was unlikely to influence childhood SHS exposure, it could not be a confounder of the association between childhood SHS exposure and times of pregnancy loss. Fifth, we did not collect any information on ventilation system of the respondents' houses. However, since all participants in our study were aged 50 years or above and were born before 1953, the ventilation systems of the houses where they lived in childhood (ie, before 1971) were almost the same at that time in China. Thus, it is unlikely to confound the results. Sixth, since information on age of (first) pregnancy loss was not available in this study, the association of childhood SHS exposure in childhood with age of (first) pregnancy loss could not be examined. We can add questions about the age of pregnancy loss in further follow-up interviews. Finally, we cannot examine the association of SHS exposure at different periods of the life course and stages of pregnancy with pregnancy loss of our participants because of the lack of detailed information on participants' SHS exposure during each of their pregnancies.

In conclusion, our study showed that childhood SHS exposure was associated with higher risks of pregnancy loss. Given that the participants' SHS exposure reflects the societal smoking prevalence from $\sim 50$ years ago, when cigarette smoking was much less popular than today (note that annual sales of cigarettes in China increased from 80 billion in 1952 to 2375.2 billion in 2010), ${ }^{34}$ a high level of exposure in China in recent years is expected, which would lead to a substantially higher healthcare burden related to pregnancy loss, if a causal relationship can be established. Our findings support the enactment of stringent national smoke-free laws and strict enforcement in China, and promotion of smoke-free homes to protect children, as well as the need for campaigns to change social norms of smoking and passive smoking.

\section{What this paper adds}

Evidence from population-based studies on childhood secondhand smoke (SHS) exposure and pregnancy loss in adulthood is limited. We examined and found the association of childhood SHS exposure with pregnancy loss in the Guangzhou Biobank Cohort Study (GBCS), the largest population-based cohort study of middle-aged and older Chinese people in southern China.

Acknowledgements The authors thank Professor R Peto, Dr Z. M. Chen and colleagues of the Clinical Trial Service Unit, the University of Oxford for their support and the Guangzhou Health and Happiness Association for Respectable Elders for recruiting the participants. The Guangzhou Biobank Cohort Study investigators included: the Guangzhou No. 12 Hospital: X. Q. Lao, W Z, M Cao, T Zhu, B. Liu and CJ (Co-PI); the University of Hong Kong: G N Thomas, C M Schooling, S M McGhee, R F Fielding, G M Leung and THL (Co-PI); and the University of Birmingham: P Adab, G N Thomas and KKC (Co-PI).

Contributors SY, LX and YH contributed to data analysis and manuscript writing CJ, KKC, YJ and WZ contributed to study design and data collection. THL contributed to study design, manuscript revision and approval of the final submission. All authors contributed to the drafting and editing of this manuscript and approved the final version submitted for publication.

Funding This study was supported by research grants from the Guangdong Natural Science Foundation of China, Guangdong, China (Grant number:

9451062001003477), the Guangzhou Science and Information Bureau, Guangzhou, China (2012J5100041), the National Natural Science Foundation of China (81373080) and the Beijing Municipal Science and Technology Commission (Z121107001012070).

Competing interests None declared.

\section{Patient consent Obtained.}

Ethics approval The study has ethics approval from the Guangzhou Medical Ethics Committee of the Chinese Medical Association, Guangzhou, China.

Provenance and peer review Not commissioned; externally peer reviewed.

Open Access This is an Open Access article distributed in accordance with the Creative Commons Attribution Non Commercial (CC BY-NC 4.0) license, which permits others to distribute, remix, adapt, build upon this work non-commercially, and license their derivative works on different terms, provided the original work is properly cited and the use is non-commercial. See: http://creativecommons.org/ licenses/by-nc/4.0/

\section{REFERENCES}

1 Gaskins AJ, Rich-Edwards JW, Hauser R, et al. Prepregnancy dietary patterns and risk of pregnancy loss. Am J Clin Nutr 2014;100:1166-72.

2 Liu B, Gao ES. Risk factors for spontaneous abortion of Chinese married women at reproductive age. Chin Public Health 2002;18:890-2.

3 Kumar S. Occupational, environmental and lifestyle factors associated with spontaneous abortion. Reprod Sci 2011;18:915-30.

4 US Department of Health Human Services. The health consequences of smoking50 years of progress: a report of the surgeon general. Atlanta, GA: US Department of Health and Human Services, Centers for Disease Control and Prevention, National Center for Chronic Disease Prevention and Health Promotion, Office on Smoking and Health, 2014;17.

5 IARC Working Group on the Evaluation of Carcinogenic Risks to Humans. Tobacco smoke and involuntary smoking. IARC Monogr Eval Carcinog Risks Hum 2004:83:1-1438.

6 Venners SA, Wang X, Chen C, et al. Paternal smoking and pregnancy loss: a prospective study using a biomarker of pregnancy. Am J Epidemiol 2004;159:993-1001.

7 Meeker JD, Benedict MD. Infertility, pregnancy loss and adverse birth outcomes in relation to maternal secondhand tobacco smoke exposure. Curr Womens Health Rev 2013;9:41-9. 
8 Windham GC, Swan SH, Fenster L. Parental cigarette smoking and the risk of spontaneous abortion. Am J Epidemiol 1992;135:1394-403.

9 Pineles BL, Park E, Samet JM. Systematic review and meta-analysis of miscarriage and maternal exposure to tobacco smoke during pregnancy. Am J Epidemiol 2014;179:807-23.

10 Hyland A, Piazza KM, Hovey KM, et al. Associations of lifetime active and passive smoking with spontaneous abortion, stillbirth and tubal ectopic pregnancy: a cross-sectional analysis of historical data from the Women's Health Initiative. Tob Control 2015;24:328-35.

11 Peppone LJ, Piazza KM, Mahoney MC, et al. Associations between adult and childhood secondhand smoke exposures and fecundity and fetal loss among women who visited a cancer hospital. Tob Control 2008;18:115-20.

12 Meeker JD, Missmer SA, Vitonis AF, et al. Risk of spontaneous abortion in women with childhood exposure to parental cigarette smoke. Am J Epidemiol 2007;166:571-5

13 Barakat-Haddad C, Elliott S, Pengelly D. Childhood Exposure to Air Pollution as a Potential Contributor of Chronic Non-respiratory Inflammatory Disorders: a Longitudinal Prospective Cohort Study in Hamilton, Canada. J Environ Prot 2013:4:779-88.

14 West HW, Juonala M, Gall SL, et al. Exposure to parental smoking in childhood is associated with increased risk of carotid atherosclerotic plaque in adulthood: the cardiovascular risk in young Finns study. Circulation 2015;131:1239-46.

15 Li Q, Hsia J, Yang G. Prevalence of smoking in China in 2010. N Engl J Med 2011:364:2469-70.

16 King BA, Mirza SA, Babb SD. A cross-country comparison of secondhand smoke exposure among adults: findings from the Global Adult Tobacco Survey (GATS). Tob Control 2013;22:e5

17 Jiang C, Thomas GN, Lam TH, et al. Cohort profile: the Guangzhou Biobank Cohort Study, a Guangzhou-Hong Kong-Birmingham collaboration. Int J Epidemiol 2006:35:844-52

18 Centers for Disease Control and Prevention (CDC). Cigarette smoking among adults —United States, 2006. MMWR Morb Mortal Wkly Rep 2007;56:1157-61.

19 Yang $S$, Jin $Y, H e ~ Y$, et al. Childhood Passive Smoking Exposure and Age at Menarche in Chinese Women Who Had Never Smoked: the Guangzhou Biobank Cohort Study. PLOS ONE 2015;10:e0130429.
20 Agarwal K, Alfirevic Z. Pregnancy loss after chorionic villus sampling and genetic amniocentesis in twin pregnancies: a systematic review. Ultrasound Obstet Gynecol 2012;40:128-34.

21 Huang FQ, Du CL, Sun MH, et al. [Propensity score matching in SPSS]. J Southern Medical University 2015;35(11):1596-601.

22 Austin PC. A critical appraisal of propensity-score matching in the medical literature between 1996 and 2003. Stat Med 2008;27:2037-49.

23 Oliver A, Overton C. Diagnosis and management of miscarriage. Practitioner 2014;258:25-8, 3.

24 Lamont K, Scott NW, Jones GT, et al. Risk of recurrent stillbirth: systematic review and meta-analysis. BMJ 2015;350:h3080.

25 Austin PC. Optimal caliper widths for propensity-score matching when estimating differences in means and differences in proportions in observational studies. Pharm Stat 2011;10:150-61

26 Augood C, Duckitt K, Templeton AA. Smoking and female infertility: a systematic review and meta-analysis. Hum Reprod 1998;13:1532-9.

27 Zdravkovic T, Genbacev 0, McMaster MT, et al. The adverse effects of maternal smoking on the human placenta: a review. Placenta 2005;26 (Suppl A):S81-6.

28 Talbot P. In vitro assessment of reproductive toxicity of tobacco smoke and its constituents. Birth Defects Res C Embryo Today 2008;84:61-72.

29 Soares SR, Melo MA. Cigarette smoking and reproductive function. Curr Opin Obstet Gynecol 2008;20:281-91.

30 Benedict MD, Missmer SA, Ferguson KK, et al. Secondhand tobacco smoke exposure is associated with prolactin but not thyroid stimulating hormone among nonsmoking women seeking in vitro fertilization. Environ Toxicol Pharmacol 2012;34:761-7.

31 Chen $C$, Wang $X$, Wang $L$, et al. Effect of environmental tobacco smoke on levels of urinary hormone markers. Environ Health Perspect 2005;113:412-17.

32 Iñiguez $C$, Ballester $F$, Amorós $R$, et al. Active and passive smoking during pregnancy and ultrasound measures of fetal growth in a cohort of pregnant women. J Epidemiol Community Health 2012;66:563-70.

33 Yin $\mathrm{P}$, Jiang $\mathrm{C}$, Cheng $\mathrm{K}$, et al. Passive smoking exposure and risk of COPD among adults in China: the Guangzhou Biobank Cohort Study. Lancet 2007:370:751-7.

34 Zhang WS, Jiang CQ, Cheng KK, et al. Alcohol sensitivity, alcohol use and hypertension in an older Chinese population: the Guangzhou Biobank Cohort Study. Hypertens Res 2009;32:741-7. 